\title{
ADMINISTRATION OF LOW-DOSE LIPOPOLYSACCHARIDE INDUCES HELLP-LIKE SYNDROME (HEMOLYSIS, ELEVATED LIVER ENZYMES AND LOW PLATELETS) IN PREGNANT RATS: INVOLVEMENT OF MACROPHAGES IN ITS PATHOGENESIS
}

\author{
Hiroaki Nakamura ${ }^{1,3}$, Naohiko Umesaki ${ }^{2}$, Sachio Ogita ${ }^{2}$ and Kenji Kaneda ${ }^{1}$ \\ ${ }^{1}$ Department of Anatomy and ${ }^{2}$ Department of Obstetrics and Gynecology, Osaka City University Medical School, Abenoku, Osaka \\ 545 , Japan
}

\begin{abstract}
HELLP syndrome (hemolysis, elevated liver enzymes and low platelets) is one of serious complications of human pregnancy, but its pathogenesis is poorly understood. The present study has revealed that intravenous administration of low-dose $(0.2 \mathrm{mg} / \mathrm{kg}$ b.w.) of lipopolysaccharide (LPS) into pregnant rats induces laboratory and histopathologic abnormalities similar to those of human HELLP syndrome. Histological lesions were restricted to the liver and did not include distinctive features of disseminated intravascular coagulation (DIC) such as renal cortical necrosis. Prominent fibrin deposits were seen along the hepatic sinusoids, followed by the confluent hepatic necrosis in the periportal zone. During pregnancy, liver macrophages increased in number. Blockade of liver macrophages by gadolinium chloride prevented the development of HELLP-like syndrome in LPS-treated pregnant rats without lowering the plasma level of tumor necrosis factor-alpha (TNF- $\alpha$ ). Hysterectomy performed immediately before LPS injection did not decrease the maternal mortality nor reduce the liver injury. These results indicate that primed liver macrophages induced during pregnancy are responsible for the development of LPS-induced HELLP-like syndrome in rats and that the contribution of TNF- $\alpha$ or substances present in the feto-placental unit to the pathogenesis may be slight.
\end{abstract}

The term HELLP syndrome was given to a special group of patients with toxemia of pregnancy which accompanies hemolysis, elevated liver enzymes and low platelets (24). Liver biopsy obtained from patients with HELLP syndrome exhibits periportal hepatocellular necrosis with a fibrin exudate, in contrast to the pericentral lesions in the acute fatty liver of pregnancy (3). For all the patients with HELLP syndrome, immediate delivery has been indicated because of the high maternal and fetal mortality (3).

The pathogenesis of HELLP syndrome is poorly understood. It is reported that HELLP syndrome is

${ }^{3}$ Corresponding author: Tel: 81-6-645-2011, Fax: 81-6646-3603 often associated with preeclampsia (23). Clinical symptoms characteristic of preeclampsia such as hypertension and proteinuria may be, however, absent or slight in HELLP syndrome (20). Another common phenomenon seen in preeclampsia is disseminated intravascular coagulation (DIC) which causes renal cortical necrosis. Although the relationship of HELLP syndrome with DIC is still controversial $(1,20,21,23)$, it is reported that DIC develops only in less than $5 \%$ of patients with HELLP syndrome (21). When HELLP syndrome is associated with DIC, the frequency of renal and pulmonary complications increases (21).

Experimentally, systemic administration of lipopolysaccharide (LPS) into pregnant animals causes renal cortical necrosis via generalized 
Shwartzman reaction (17) or preterm parturition (6). Intravenous infusion of ultra-low-dose LPS into pregnant rats induces disorders which resemble to human preeclampsia (5). Wong (25) reported that pregnant rats which received more than 0.25 $\mathrm{mg}$ (approximately $1 \mathrm{mg} / \mathrm{kg} \mathrm{b.w.)} \mathrm{of} \mathrm{LPS} \mathrm{displayed}$ pathologic features of DIC with glomerular fibrin deposits and renal cortical necrosis, while those treated with less than $0.2 \mathrm{mg}$ of LPS did not. In order to establish rat HELLP-like syndrome not associated with manifest DIC, we used a lower dose of LPS than induces renal cortical necrosis (25) and examined whether the disorders induced by low-dose LPS in pregnant rats share laboratory and histopathologic abnormalities with human HELLP syndrome. Furthermore, based on the assumption that macrophages, a target of LPS, or fetoplacental tissue, a large reservoir of tissue thromboplastin and also a target of LPS (19), might contribute to the development of disorders, we investigated the suppressive effects of gadolinium chloride, which blocks phagocytosis by macrophages (13) and eliminates liver macrophages (12), and those of hysterectomy on the induction of HELLP-like syndrome in pregnant rats.

\section{MATERIALS AND METHODS}

\section{Animals}

Twelve weeks-old, non-pregnant and pregnant Sprague-Donlew rats on 14th gestational day were purchased from Shizuoka Laboratory Animal Center (Shizuoka, Japan). They were fed of standard chow pellet and water ad libitum under a specific pathogen-free condition. Experiments were performed in accordance with the standard guideline for animal experiments of the Osaka City University Medical School.

\section{Reagents}

LPS (Lipopolysaccharides E. coli. 055: B5) was purchased from Difco (Detroit, MI). Gadolinium chloride $\left(\mathrm{GdCl}_{3}-6 \mathrm{H}_{2} \mathrm{O}\right)$ was purchased from Wako Pure Chemicals (Osaka).

\section{Treatments}

Non-pregnant and pregnant rats on 17 th gestational day were subjected to a single intravenous (i.v.) injection of $0.2,0.25,0.5,1$ or $2 \mathrm{mg} / \mathrm{kg}$ b.w. of LPS. As a control, saline was i.v. injected. Animals were sacrificed $24 \mathrm{~h}$ after LPS or saline injection. Some animals received an i.v. injection of 10 $\mathrm{mg} / \mathrm{kg}$ b.w. of $\mathrm{GdCl}_{3} 24 \mathrm{~h}$ prior to LPS administration. Hysterectomy was performed on 17 th gestational day. Under ether anesthesia, abdomen was opened. After the ligation of the uterine arteries and veins, the uterus was resected and taken out. LPS was i.v. injected 0 or $24 \mathrm{~h}$ after the operation.

\section{Laboratory Data of the Peripheral Blood}

Under ether anesthesia, abdomen was opened $8 \mathrm{~h}$ after the injection of LPS or saline. Maternal peripheral blood was taken from the vena cava inferior. We measured plasma levels of alanine aminotransferase (GPT), aspartate aminotransferase (GOT), lactate dehydrogenase (LDH), total bilirubin (T-Bil), indirect type bilirubin (ID-Bil), blood urea nitrogen $(\mathrm{BUN})$, creatinine (Cre), sodium $(\mathrm{Na})$, potassium $(\mathrm{K})$, and chloride $(\mathrm{Cl})$. Number of erythrocytes, leukocytes, and platelets in the peripheral blood were also counted.

\section{Histology}

Various organs such as liver, lungs, spleen, kidneys, intestine and feto-placental unit were taken out and fixed in $10 \%$ formalin. Paraffin sections were stained with hematoxylin and eosin (H-E). For electron microscopy, the liver was perfusionfixed with $1.5 \%$ glutaraldehyde in $0.062 \mathrm{M}$ cacodylate buffer, $\mathrm{pH} 7.4$, plus $1 \%$ sucrose. Small blocks were post-fixed in $1 \% \mathrm{OsO}_{4}$ for $2 \mathrm{~h}$, dehydrated and embedded in polybed (Polyscience, Warrington, PA). Semithin sections were stained with toluidine blue. Ultrathin sections were stained with uranyl acetate and lead citrate and observed under a JEM 1200EX electron microscope (JEOL, Tokyo).

\section{Morphometry}

Three non-pregnant and three pregnant rats were used for morphometry. We examined toluidine blue-stained sections at the magnification of $\times 400$ and counted the number of macrophages within 20 microscopic fields $\left(=1.68 \mathrm{~mm}^{2}\right)$ of parenchymal area of the liver. Average cell density (number/1.68 $\mathrm{mm}^{2}$ ) of three rats was calculated for each group.

\section{Quantitation of Plasma TNF- $\alpha$}

Peripheral blood was taken $1 \mathrm{~h}$ after LPS injection. 
Table 1 Survival Rate of Non-Pregnant, Pregnant and Gadolinium Chloride $\left(\mathrm{GdCl}_{3}\right)$-Pretreated Pregnant Rats 24 h after i.v. Injection of Various Doses of LPS

\begin{tabular}{cccc}
\hline $\begin{array}{c}\text { Dose of LPS } \\
\text { (mg/kg b.w.) }\end{array}$ & $\begin{array}{c}\text { Non-pregnant } \\
\text { rats }\end{array}$ & $\begin{array}{c}\text { Pregnant } \\
\text { rats }\end{array}$ & $\begin{array}{c}\mathrm{GdCl}_{3} \text {-pretreated pregnant } \\
\text { rats }\end{array}$ \\
\hline 0.1 & $\mathrm{nt}$ & $5 / 5(100 \%)$ & $\mathrm{nt}$ \\
0.2 & $5 / 5(100 \%)$ & $6 / 12(50 \%)$ & $13 / 13(100 \%)$ \\
0.25 & $\mathrm{nt}$ & $3 / 5(60 \%)$ & $\mathrm{nt}$ \\
0.5 & $\mathrm{nt}$ & $2 / 5(40 \%)$ & $\mathrm{nt}$ \\
1 & $6 / 6(100 \%)$ & $5 / 11(45 \%)$ & $\mathrm{nt}$ \\
2 & $6 / 6(100 \%)$ & $1 / 4(25 \%)$ & $\mathrm{nt}$ \\
\hline
\end{tabular}

nt, not tested

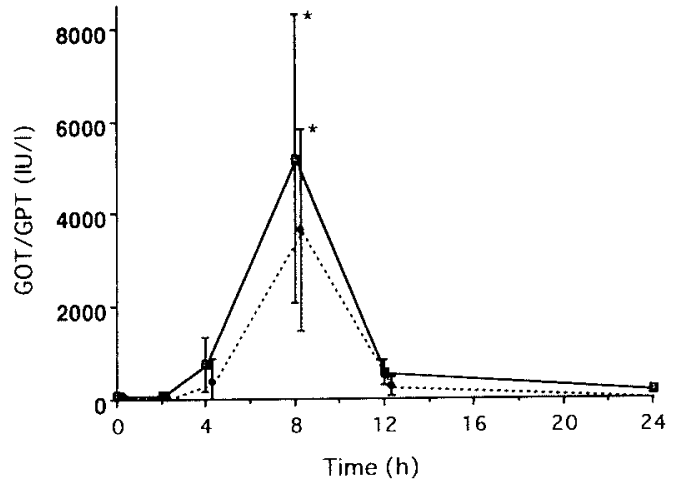

Fig. 1 Time course of plasma GOT (-) and GPT $(-\cdots)$ in the pregnant rats on 17 th gestational day after i.v. injection $0.2 \mathrm{mg} / \mathrm{kg}$ b.w. of LPS. Three to six animals were used in each time interval. Each value represents mean $\pm \mathrm{SD}$. ${ }^{*} P<0.01$ vs value at $0 \mathrm{~h}$

We used an enzyme-linked immunoabsorbent assay kit for murine TNF- $\alpha$ (Genzyme, Cambridge, MA). The plasma level of TNF- $\alpha$ was determined by the absorbance value.

\section{Statistics}

Significant difference between two populations was analyzed by unpaired Student's $t$-test. Data were expressed as mean values \pm standard deviation (SD).

\section{RESULTS}

Survival Rate, Laboratory Data and Histopathology of Pregnant Rats after LPS Administration

The lethal toxic effect of LPS on pregnant rats was dose-dependent between 0.1 and $2 \mathrm{mg} / \mathrm{kg}$ b.w.
(Table 1). In pregnant rats treated with $0.2 \mathrm{mg} / \mathrm{kg}$ b.w. of LPS, maternal mortality was approximately $20 \%$ at $3 \mathrm{~h}$ after LPS injection, elevated to $40-60 \%$ at $12 \mathrm{~h}$, but did not further increase thereafter. Fetuses were, however, all dead. On the other hand, non-pregnant rats which received $0.2,1$ or 2 $\mathrm{mg} / \mathrm{kg} \mathrm{b.w}$. of LPS all survived. We used the dose of $0.2 \mathrm{mg} / \mathrm{kg}$ b.w. in the following experiments because it was the minimal dose which made obvious difference in the survival rate between pregnant and non-pregnant rats.

We next examined laboratory and pathologic abnormalities in LPS-treated pregnant rats and compared them with those reported in human HELLP syndrome. By LPS injection, plasma GOT/GPT levels started to rise at $4 \mathrm{~h}$, reached a peak at $8 \mathrm{~h}$, and then declined (Fig. 1). We therefore measured other laboratory data of the peripheral blood at $8 \mathrm{~h}$ (Table 2). Although plasma GOT/GPT and LDH were also elevated in LPStreated non-pregnant rats, the degree of the elevation was much higher $(P<0.01)$ in pregnant rats (Table 2). On the other hand, platelet count was decreased to a similar extent between non-pregnant and pregnant rats. The plasma from LPS-treated pregnant rats was pinkish due to the hemolysis, in contrast to a normal color in LPS-treated non-pregnant rats. Elevation of ID-Bil in LPS-treated pregnant rats was also indicative for hemolysis. Renal function as evaluated by the plasma concentration of creatinine was normal (Table 2).

Light microscopically, periportal hepatocellular necrosis occurred in pregnant rats $8 \mathrm{~h}$ after LPS injection (Fig. 2b), but did not in non-pregnant rats (Fig. 2a). Pathologic changes of renal cortical necrosis and gastrointestinal tract hemorrhage were not observed (Fig. 3). Under an electron microscope, platelets began to adhere to the sinusoidal 


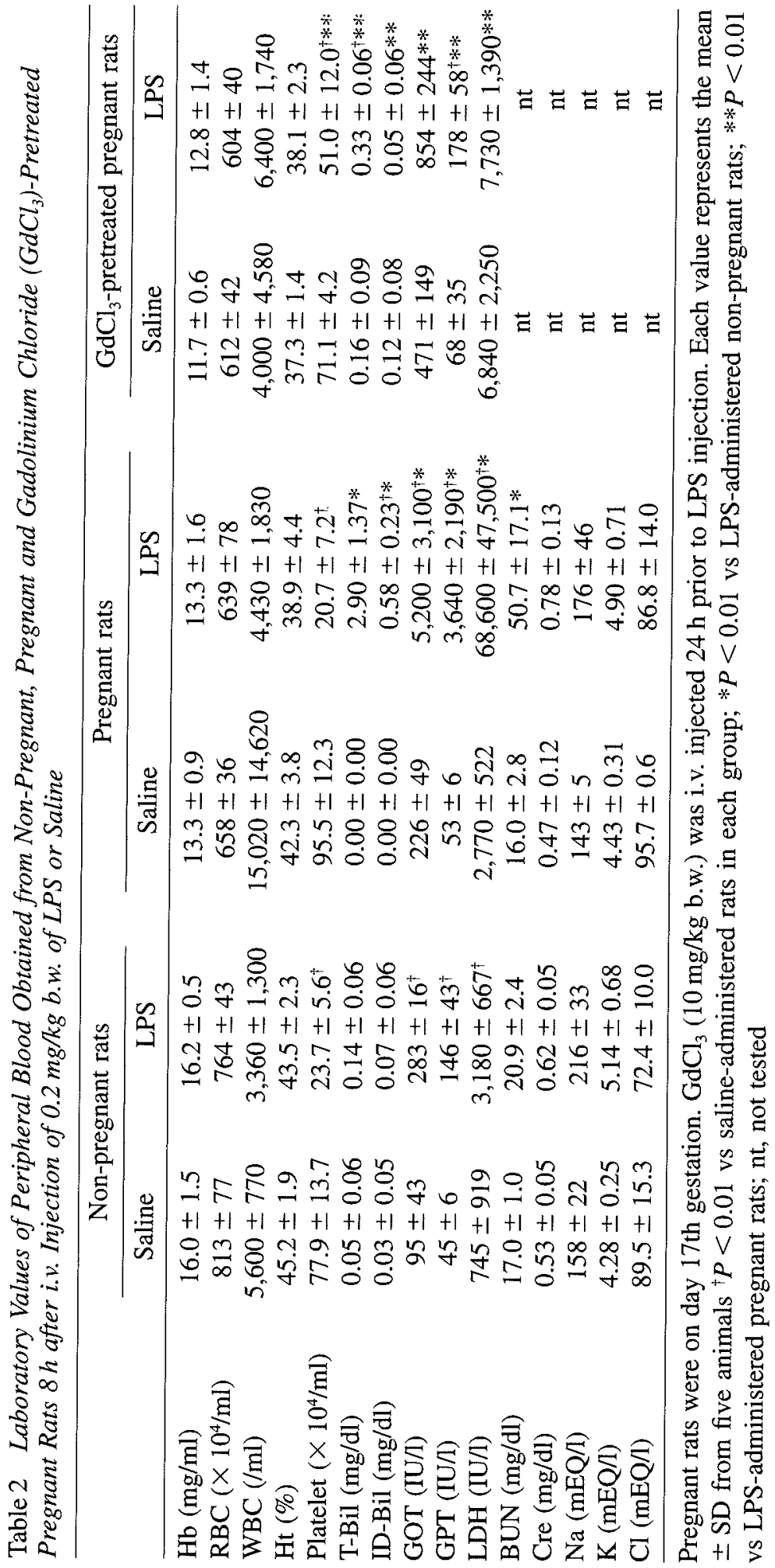



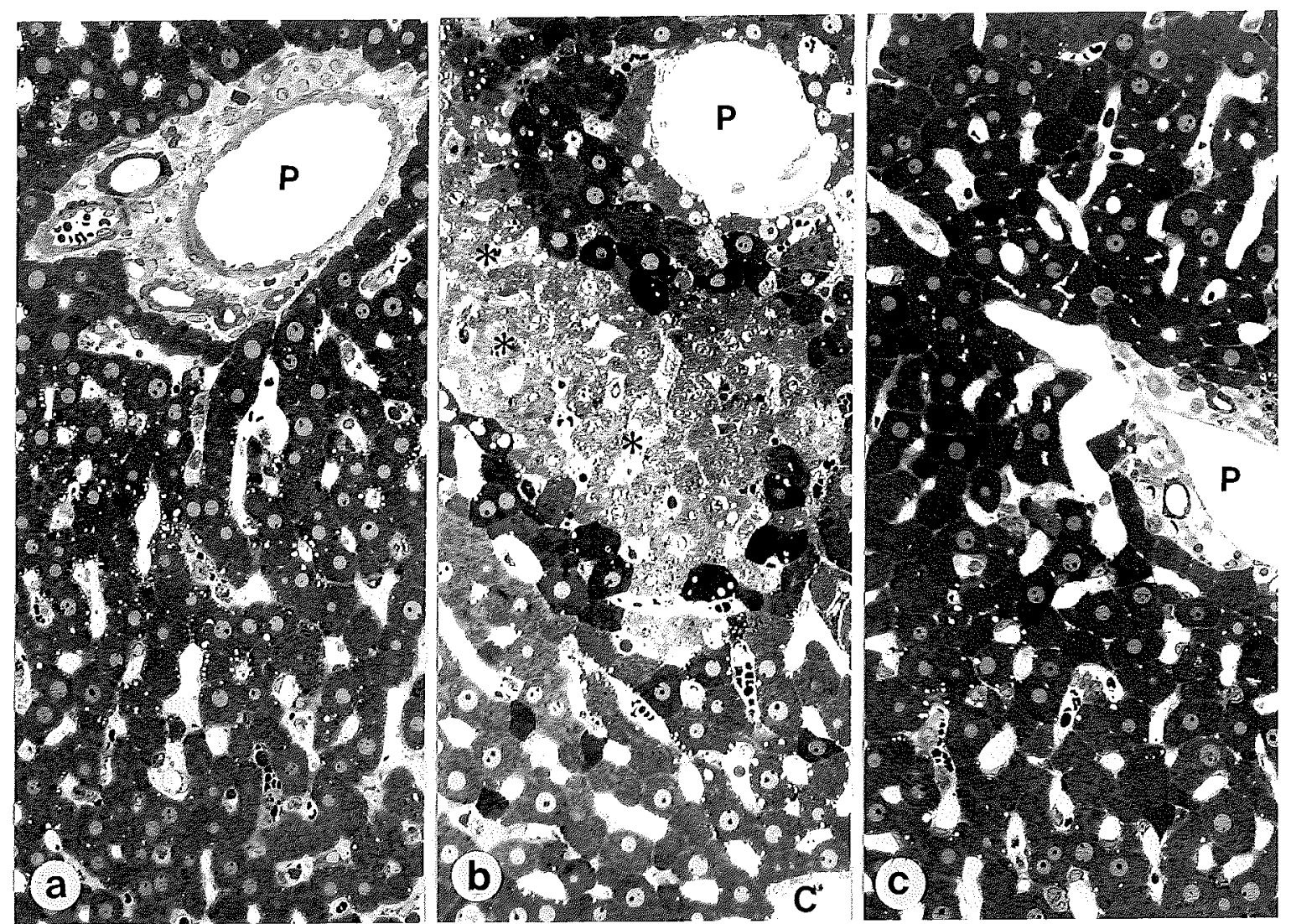

Fig. 2 Light micrographs of the livers $8 \mathrm{~h}$ after i.v. injection of $0.2 \mathrm{mg} / \mathrm{kg}$ b.w. of LPS. a, non-pregnant rats; $\mathrm{b}$, pregnant rats; c, $\mathrm{GdCl}_{3}$-pretreated pregnant rats. No necrotic changes of hepatocytes are seen in non-pregnant or $\mathrm{GdCl}_{3}-$ pretreated pregnant rats, while periportal hepatocellular necrosis (asterisks) is evident in pregnant rats. $P$, portal veins; $C$, central veins. Toluidine blue-staining. $\times 250$

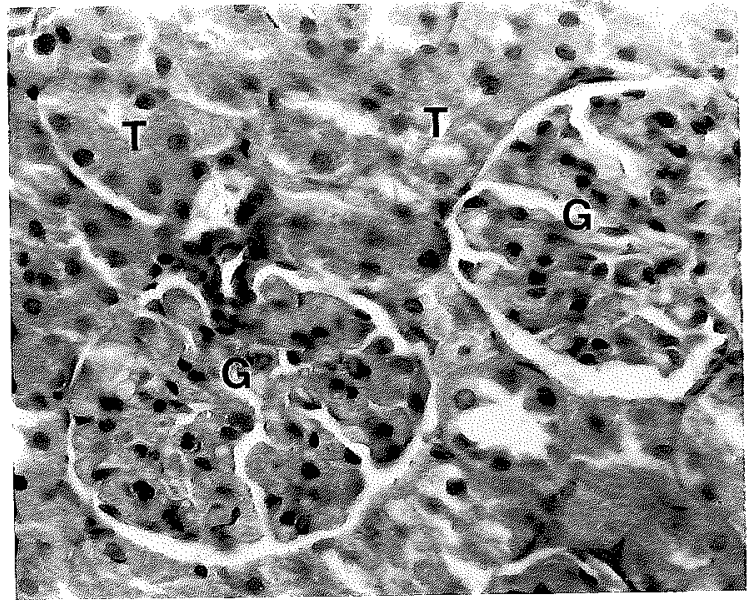

Fig. 3 A light micrograph of the kidney in pregnant rat $8 \mathrm{~h}$ after i.v. injection of $0.2 \mathrm{mg} / \mathrm{kg}$ b.w. of LPS. No pathologic changes are seen in the glomerulus $(\mathrm{G})$ and renal tubules $(\mathrm{T})$. H-E staining. $\times 400$ endothelial cells at $2 \mathrm{~h}$ (Fig. 4a). Prominent fibrin deposits were seen on the surface of Kupffer cells or sinusoidal endothelial cells as well as in the space of Disse (Fig. 4, a and b). Endothelial disruption or detachment was not obvious. At $8 \mathrm{~h}$, hepatocytes underwent necrosis. Neutrophils were accumulated around the degenerated hepatocytes.

\section{Involvement of Macrophages in the} Development of HELLP-like Syndrome of Rats

In order to demonstrate the involvement of macrophages in the development of LPS-induced HELLP-like syndrome of rats, we investigated the effects of $\mathrm{GdCl}_{3}$, a blocking agent of macrophages, on the mortality or laboratory and pathologic changes of LPS-treated pregnant rats.

Pretreatment of pregnant rats with $\mathrm{GdCl}_{3}$ reduced LPS-induced high maternal mortality and laboratory abnormalities. The maternal survival 


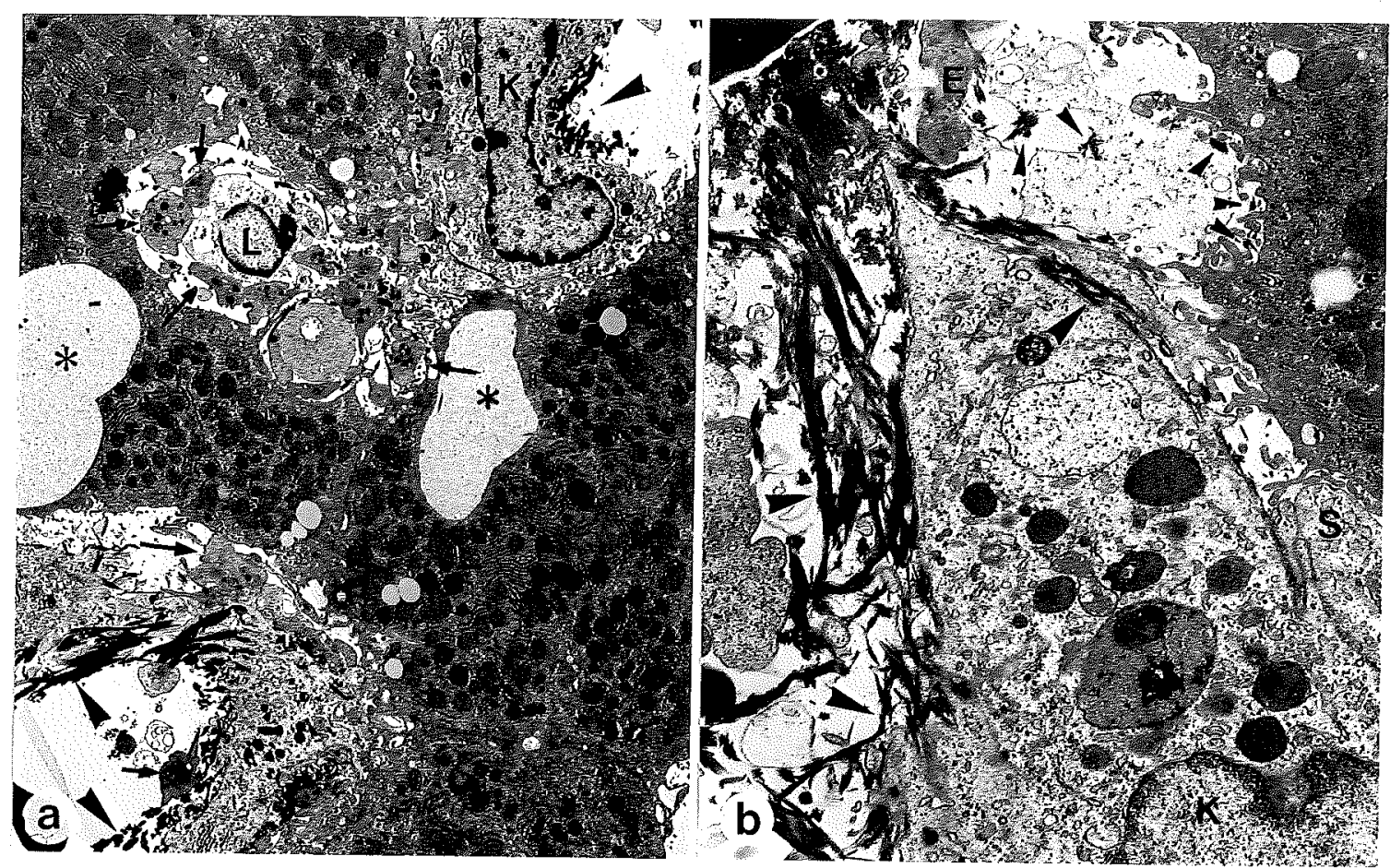

Fig. 4 Electron micrographs of the livers of pregnant rats $2 \mathrm{~h}$ after i.v. injection of $0.2 \mathrm{mg} / \mathrm{kg} \mathrm{b.w}$. of LPS. Prominent fibrin deposits (large arrowheads) are seen on the surface of Kupffer cells $(K)$ and sinusoidal endothelial cells $(E)$. A small amount of fibrin deposits (small arrowheads in Fig. 4b) exist also in the space of Disse and on the hepatocytes. Platelets (arrows) are accumulated in the sinusoid. $L$, lymphocytes; $S$, stellate cells; asterisks, lipid droplets. a, $\times 2,700 ; b, \times 7,300$

rate increased from $50 \%$ (without $\mathrm{GdCl}_{3}$ ) to $100 \%$ (with $\mathrm{GdCl}_{3}$ ) (Table 1), although fetuses were all dead even when pregnant rats survived. LPSinduced elevation of T-Bil, ID-Bil, GOT/GPT and LDH as well as reduction of platelet count were significantly suppressed by the pretreatment with $\mathrm{GdCl}_{3}$ (Table 2). The color of the plasma from $\mathrm{GdCl}_{3}$-pretreated animals was not pinkish. Histologically, neither fibrin deposits nor hepatocellular necrosis was observed in the liver (Fig. 2c).

\section{Number of Liver Macrophages in Non-Pregnant and Pregnant Rats}

From the present results that liver injury was the main pathologic feature of rat HELLP-like syndrome and that macrophages were involved in the development of the disorder, we next examined the numerical difference of liver macrophages between non-pregnant and pregnant rats before the LPS administration. There were $270 \pm 44$ and $436 \pm 50$ macrophages per unit square $\left(=1.68 \mathrm{~mm}^{2}\right)$ of the liver parenchyma in non-pregnant $(n=3)$ and pregnant rats $(\mathrm{n}=3)$, respectively, with significant difference $(P<0.05)$ between two groups.

\section{Plasma TNF- $\alpha$ Levels}

Without LPS administration, TNF- $\alpha$ was not detected in the peripheral blood of non-pregnant and pregnant rats. One hour after LPS injection, it increased prominently in both groups (Fig. 5). Although the value was somewhat higher in pregnant rats, there was no significant difference between two groups. Pretreatment of pregnant rats with $\mathrm{GdCl}_{3}$ lowered plasma levels of TNF- $\alpha$ to some extent, but not significantly, compared to $\mathrm{GdCl}_{3}$-non-pretreated pregnant rats (Fig. 5).

\section{Contribution of the Feto-Placental Unit to LPS-Induced Liver Injury and Lethal Toxicities}

Pregnant rats which received LPS immediately after the hysterectomy showed a comparable degree of liver injury to that of non-operated preg- 


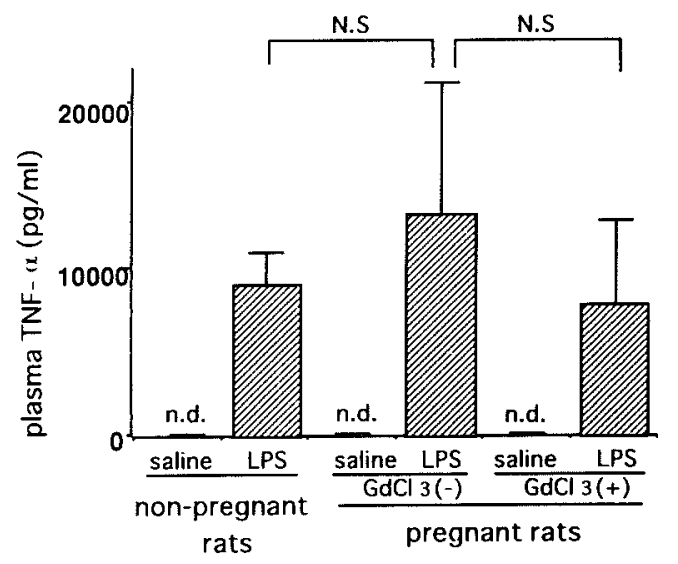

Fig. 5 Plasma TNF- $\alpha$ levels in non-pregnant, pregnant and $\mathrm{GdCl}_{3}$-pretreated pregnant rats $1 \mathrm{~h}$ after i.v. injection of $0.2 \mathrm{mg} / \mathrm{kg} \mathrm{b}$.w. of LPS. Each value represents the mean \pm SD. n.d., not detected; NS, not significant

nant rats (Fig. 6). There was no difference in the maternal survival rate at $8 \mathrm{~h}$ between hysterectomized and non-hysterectomized rats, i.e. 50\% $(4 / 8)$ and $50 \%(6 / 12)$, respectively. In contrast, hysterectomy performed $24 \mathrm{~h}$ prior to LPS injection significantly lowered plasma levels of GOT/GPT (Fig. 6) and increased maternal survival rate from $50 \%(6 / 12)$ to $100 \%(5 / 5)$.

\section{DISCUSSION}

Clinical and experimental studies have been performed to reveal the cause of human HELLP syndrome. Several pathogenetic findings such as the presence of maternal immunologic alterations in the patients $(9,10)$ and the possible contribution of vasospasm of the hepatic artery (11) have been presented [although there is also a report that increased resistance of the hepatic artery is a general feature of human preeclampsia independently of the presence of HELLP syndrome (19)], but the pathogenesis is not fully elucidated. Since LPS has been used for the analysis of preeclampsia in experimental animals $(5,17)$, in this study, for the purpose of making a model of rat HELLP-like syndrome, we investigated LPS-induced disorders in pregnant rats in regard to the similarity to human HELLP syndrome.

By the use of a lower dose of LPS than induces glomerular fibrin deposits and renal cortical necrosis, characteristic of DIC (25), pregnant rats exhibited laboratory and histopathologic abnormalities which mimic predominant features of human

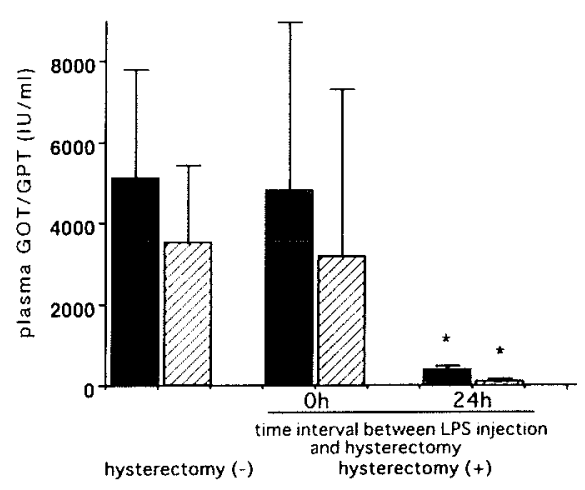

Fig. 6 Effects of hysterectomy on LPS-induced liver injury in pregnant rats. Hysterectomy was performed 0 or $24 \mathrm{~h}$ prior to LPS injection. Plasma GOT ( $\square$ ) and GPT ( $Z Z A$ ) were measured $8 \mathrm{~h}$ after i.v. injection of 0.2 $\mathrm{mg} / \mathrm{kg}$ b.w. of LPS. Each value represents the mean \pm $\mathrm{SD} .{ }^{*} P<0.01$ vs values of non-hysterectomized rats

HELLP syndrome $(3,24)$, i.e., elevation of liver enzymes, reduction of platelet count, hemolysis, periportal hepatocellular necrosis with fibrin deposits along the sinusoidal wall, and high incidence of maternal and fetal death. This fact suggests that LPS-induced HELLP-like syndrome in pregnant rats may be a mild form of DIC.

Low platelet count in the peripheral blood, one of major signs of human HELLP syndrome (24), was found in rat HELLP-like syndrome. However, similar decrease of platelets also occurred in LPStreated non-pregnant rats which did not develop HELLP-like syndrome. It is reported that translocation of platelets from the peripheral blood into the liver occurs in normal mice after LPS administration (4). The present results indicate that low platelet count is not related to the development of HELLP-like syndrome, consistent with the previous reports that platelets are not involved in LPSinduced generalized Shwartzman reaction in pregnant rats (16) or endotoxin shock in estrogen-pretreated dogs (7).

Liver macrophages are assumed to be responsible for LPS-induced HELLP-like syndrome because they incorporate i.v. injected LPS via receptor-mediated endocytosis. By the pretreatment with $\mathrm{GdCl}_{3}$, which blocks phagocytosis by macrophages (13) and eliminates liver macrophages (12), pregnant rats were completely protected from the laboratory and pathologic abnormalities of LPS-induced HELLP-like syndrome except the fetal death, indicating the involvement of liver macrophages in the develop- 
ment of this disorder. Morphometric analysis has demonstrated that the number of liver macrophages of pregnant rats was higher than that of non-pregnant ones. High levels of estrogens during pregnancy might be attributed to the increase of liver macrophages because in vivo administration of estrogens induces enlargement and proliferation of Kupffer cells and enhances their phagocytic activity (15).

Pregnancy is regarded as an equivalent of the preparative step of generalized Shwartzman reaction $(17,25)$. Increased number of liver macrophages observed in pregnant rats are considered to represent primed macrophages which lead to the Shwartzman reaction after a single injection of LPS, although the reaction induced in the present model was restricted to the liver due to the low dose of LPS used. Similar pathologic changes of intrasinusoidal fibrin deposits and confluent hepatocellular necrosis as seen here are also reported in the rats treated with Propionibacterium acnes/LPS (26), in which TNF or superoxide anion released from activated macrophages are considered to be responsible for the injury (2). TNF- $\alpha$, however, does not seem to play major roles in the pathogenesis of rat HELLP-like syndrome because pretreatment with $\mathrm{GdCl}_{3}$, which did not significantly lower plasma levels of TNF- $\alpha$, consistent with a previous study (14), well protected mice from the development of HELLP-like syndrome and liver injury.

Since feto-placental unit is a large reservoir of thromboplastin and other coagulative factors (8), mobilization of these factors into the liver might have contributed to LPS-induced liver injury in pregnant rats. However, hysterectomy performed immediately before LPS injection did not reduce the liver injury, indicating that the liver injury is induced independently of coagulative factors present in the feto-placental unit. On the other hand, hysterectomy done $24 \mathrm{~h}$ before LPS injection well protected animals from the liver injury and maternal death, which indicates that pathognomonic factors of rat HELLP-like syndrome are closely associated with the pregnant state and may decline within $24 \mathrm{~h}$ after hysterectomy.

The mechanism of the fetal death in rat HELLPlike syndrome is not known. The placenta displayed no pathologic changes indicative of the fetal death. It is reported that elevation of cytokines such as TNF- $\alpha$ precedes LPS-induced preterm delivery in mice (6). In this study as well, fetal mortality was not improved by the pretreatment with $\mathrm{GdCl}_{3}$ which failed to reduce TNF- $\alpha$. A highly inducible form of cyclooxygenase, COX-2, which is increased in amount in the murine decidua by LPS injection, is also a candidate for the cause of fetal death (22).

This investigation was supported in part by grant from JAOG Ogyaa Donation Foundation, Tokyo, Japan.

Received 5 November 1996; and accepted 9 December 1996

\section{REFERENCES}

I. Aarnoudse J. G., Houthoff H. F., Weits J., Vellenga E. and Huisjes H. J. (1986) A syndrome of liver damage and intravascular coagulation in the last trimester of normotensive pregnancy. A clinical and histopathological study. Brit. J. Obstet. Gynaecol. 93, 145-155

2. Arai M., Mochida S., Ohno A., Ogata I. and Fujiwara K. (1993) Sinusoidal endothelial cell damage by activated macrophages in rat liver necrosis. Gastroenterology $\mathbf{1 0 4}$, 1466-1471

3. Barton J. R., Riely C. A., Adamec T. A., Shanklin D. R., Khoury A. D. and Sibal B. M. (1992) Hepatic histopathologic condition does not correlate with laboratory abnormalities in HELLP syndrome (hemolysis, elevated liver enzymes, and low platelet count). Amer: J. Obstet. Gynecol. 167, 1538-1543

4. Endo Y. and Nakamura M. (1992) The effect of lipopolysaccharide, interleukin-1 and tumor necrosis factor on the hepatic accumulation of 5-hydroxytryptamine and platelets in the mouse. Brit. J. Pharmacol. 105, 613-619

5. FaAs M. M., Schuiling G. A., Baller J. F. W., Annet VISSCHER C. and BAKKER W. W. (1994) A new animal model for human preeclampsia: Ultra-low-dose endotoxin infusion in pregnant rats. Amer: J. Obstet. Gynecol. 171, 158-164

6. Fidel P. L., Romero R., Wolf N., Cutright J., Ramirez M., Araneda H. and Cotton D. B. (1994) Systemic and local cytokine profiles in endotoxin-induced preterm parturition in mice. Amer. J. Obstet. Gynecol. 170, 1467-1475

7. From A. H., Fong J. S. C., ChIU T. and Good R. A. (1976) Role of platelets in the pathogenesis of canine endotoxin shock. Infect. Immun. 13, 1591-1594

8. Gonmori H. and TAKedA Y. (1976) Properties of human tissue thromboplastins from brain, lung, arteries and placenta. Thromb. Haemost. 36, 90-103

9. Haeger M., Unader M. and Bengtsson A. (1990) Enhanced anaphylatoxin and terminal C5b-9 complement complex formation in patients with the syndrome of hemolysis, elevated liver enzymes, and low platelet count. Obstet. Gynecol. 76, 698-702

10. Haeger M., Unader M., Norder-Hansson B., Tylman M. and Bengtsson A. (1992) Complement, neutrophil, and macrophage activation in woman with severe preeclampsia and the syndrome of hemolysis, elevated liver enzymes, and low platelet count. Obstet. Gynecol. 79, 19-26

11. Halim A., Kanayama N., Maehara K., Takahashi $M$. and Terao T. (1993) HELLP syndrome-like biochemical parameters obtained with endothelin-1 injections in rabbits. Gynecol. Obstet. Invest. 35, 193-198

12. Hardonk M. J., Dijkhuis F. W. J., Hulstaert C. E. and Koudstaal J. (1992) Heterogeneity of rat liver and spleen 
macrophages in gadolinium chloride-induced elimination and repopulation. J. Leukocyte Biol. 52, 296-302

13. Husztik E., Lazar G. and Parducz A. (1980) Electron microscopic study of Kupffer cell phagocytosis blockade induced by gadolinium chloride. Brit. J. Exp. Pathol. 61, 624-630

14. Immuro Y., Yamamoto M., Kohno H., Itakura J., Fujn H. and MATsumoto Y. (1994) Blockade of liver macrophages by gadolinium chloride reduces lethality in endotoxemic rats. Analysis of mechanisms of lethality in endotoxemia. $J$. Leukocyte Biol. 55, 723-728

15. IKEJIRI N. and TANIKAWA K. (1977) Effects of vitamin A and estrogen on the sinusoidal cells in the rat liver. In Kupffer Cells and Other Liver Sinusoidal Cells (ed. WISSE E. and KNOOK D. L.) Elsevier, Amsterdam, pp. 83-92

16. Latour J. G. and Groulx C. (1979) Antiplatelet drugs and the generalized Shwartzman reaction in the pregnant rat. $J$. Pharmacol. Exp. Ther: 211, 171-173

17. McKay D. G., Werrill S. J., Weiner A. E., Hertig A. T. and REID D. E. (1953) The pathologic anatomy of eclampsia, bilateral renal cortical necrosis, pituitary necrosis, and other acute total complications of pregnancy, and its possible relationship to the generalized Shwartzman reaction. Amer: J. Obstet. Gynecol. 66, 507-539

18. MCKay D. G. and Wong T. C. (1962) The effect of bacterial endotoxin on the placenta of the rat. Amer: J. Pathol. 42, $357-377$

19. Oosterhof H., Voorhoeve P. G. and Aarnoudse J. G. (1994) Enhancement of hepatic artery resistance to blood flow in preeclampsia in presence or absence of HELLP syndrome (hemolysis, elevated liver enzymes, and low platelets). Amer: J. Obstet. Gynecol. 171, 526-530

20. Sibai B. M. (1990) The HELLP syndrome (hemolysis, elevated liver enzymes, and low platelets): Much ado about nothing? Amer: J. Obstet. Gynecol. 162, 311-316

21. Sibai B. M., Ramadan M. K., Usta I., Salama M., MerCER B. M. and Friedman S. A. (1993) Maternal morbidity and mortality in 442 pregnancies with hemolysis, elevated liver enzymes, and low platelets (HELLP syndrome). Amer: J. Obstet. Gynecol. 169, 1000-1006

22. Silver M. R., Edwin S. S., Trautman M. S., Simmonds D. L., Branch D. W., Dudley D. J. and Mitchell M. D. (1995) Bacterial lipopolysaccharide-mediated fetal death. Production of a newly recognized form of inducible cyclooxygenase (COX-2) in murine decidua in response to lipopolysaccharide. J. Clin. Invest. 95, 725-731

23. Van Dam P. A., Renier M., Baekelandt M., Buytaert P. and UytTEnbroecK F. (1989) Disseminated intravascular coagulation and the syndrome of hemolysis, elevated liver enzymes, and low platelets in severe preeclampsia. Obstet. Gynecol. 73, 97-102

24. WEINSTEIN L. (1982) Syndrome of hemolysis, elevated liver enzymes, and low platelet count: a severe consequence of hypertension. Amer: J. Obstet. Gynecol. 142, 159-167

25. WoNG T. C. (1962) A study on the generalized Shwartzman reaction in pregnant rats induced by bacterial endotoxin. Amer: J. Obstet. Gynecol. 84, 786-797

26. Yamada S., Ogata I., Hirata K., Mochida S., Tomiya T. and Funiwara K. (1989) Intravascular coagulation in the development of massive hepatic necrosis induced by Corynebacterium parvum and endotoxin in rats. Scand. J. Gastroenterol. 24, 293-298 